\title{
FUNCIONES DE LA RESPONSABILIDAD CIVIL: CAMBIO DE PARADIGMAS EN EL SISTEMA DE DERECHO PRIVADO ARGENTINO*
}

\section{CIVIL RESPONSIBILITY'S FUNCTIONS: PARADIGMS CHANGE IN THE ARGENTINIAN PRIVATE LAW SYSTEM}

\section{SANDRA NATALIA UMANSKY}

Becaria de la Secretaría General de Ciencia y Técnica de UNNE

Facultad de Ciencias Económicas

Universidad Nacional del Nordeste

ARGENTINA

"El mundo que hemos creado es producto de nuestra forma de pensar. Es una locura pensar que el mundo pueda cambiar sin que cambien nuestros modelos mentales”. Albert Einstein 


\title{
RESUMEN
}

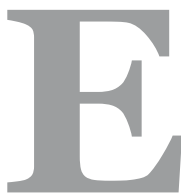

l presente artículo tiene por finalidad comentar la transformación operada en el sistema del Derecho Privado patrimonial argentino, a través de la inclusión de una variedad de funciones de la responsabilidad civil, tradicionalmente pergeñada en el Código de Vélez como compensatoria. Se ha propuesto, asimismo, analizar la evolución de estas funciones desde la incorporación de algunos institutos provenientes de distintos microsistemas del Derecho Civil, como el Derecho Ambiental y el de Consumo, para estudiar el proceso de modificación de la legislación privada argentina desde el Anteproyecto de 2012 hasta su regulación actual el Código Civil y Comercial de la Nación -en adelante CCCN-, en aras de explicitar la configuración actual del sistema de responsabilidad civil vigente. Para ello se ha realizado una investigación de abordaje cualitativo, con técnicas descriptivas y bibliográficas, caracterizada como pura, si se analizan sus objetivos extrínsecos, y longitudinal en cuanto a su temporalización. Como conclusión principal podemos derivar que la responsabilidad en el Derecho privado patrimonial argentino asume una pluralidad de funciones, centralmente preventiva y resarcitoria; y periféricamente precautoria y punitiva, debiendo el intérprete realizar un adecuado diálogo de fuentes para la articulación del sistema a fin de mantener la plena vigencia de esta polifuncionalidad.

Palabras clave: prevención, reparación, punición, precaución.

\begin{abstract}
The present article has by purpose commenting the transformation operated in patrimonial argentinean private law's system, through the inclusion of a variety of functions of the civil responsibility, traditionally sketched in Vélez' Code as compensatory. It also sets out to analyze the evolution of these functions from the incorporation of some institutes originating on different microsystems from the Civil Law, as the Environmental and Consumption Law, to study Argentina private legislation process of modification, from the First Draft of the 2012 to its present regulation Civil and Commercial Code of the Nation -from now on CCCN- for the sake of specifying the present configuration of the system of effective civil responsibility. For it, it makes an investigation of qualitative boarding, with descriptive and bibliographical techniques, characterized as pure, if their extrinsic objectives are analyzed and longitudinal, as far as its temporalization. As main conclusion it obtains that the responsibility in the Private patrimonial Argentinean Law assumes a plurality of functions, centrally preventive and compensatory and
\end{abstract}

* Este artículo fue producido en el marco del Proyecto de Investigación PI 12M003 “Funciones actuales del sistema de responsabilidad del proveedor ante el consumidor" del Grupo Interdisciplinario de Estudios sobre Consumo que integra la autora y dirige la Profesora Dra. María Laura Estigarribia Bieber. El PI está acreditado por Resolución N 135/13 del C.S. de la UNNE. 
peripherally precautory and punitive. The interpreter have the duty to make a suitable dialogue of sources for the joint of the system, mantaining the total apply of this polifunctionallity.

Keywords: prevention, reparation, punishment, precaution.

\section{1.- INTRODUCCIÓN}

En el presente artículo se realiza un análisis y una descripción de la evolución habida en cuanto a las funciones de la responsabilidad civil en el Derecho Privado Patrimonial Argentino.

Primeramente se analiza la función compensatoria como paradigma del sistema de responsabilidad civil establecida en el Código Civil de Vélez Sarsfield. Luego se estudian las posturas de algunos autores que sostenían la necesidad de dotar de otras funciones a la responsabilidad civil, para describir después la inclusión de algunas figuras jurídicas que modificaron la finalidad única.

Más adelante se relatan las soluciones brindadas por otros microsistemas como el Derecho Ambiental y el de Consumo, incluyendo los principios de prevención y precautorio, el primero, y a los daños punitivos, el segundo ${ }^{1}$, para seguir la historia jurídica del sistema hasta llegar a su configuración actual en el Código Civil y Comercial de la Nación, pasando revista por la situación del Anteproyecto y Proyecto precedentes al mismo.

\section{2.- METODOLOGía}

La investigación fue llevada a cabo a través de una estrategia de abordaje cualitativo, que “... se basa en métodos de recolección de datos sin medición numérica, como las descripciones y las observaciones..., se mueve entre los eventos y su interpretación, entre las respuestas y el desarrollo de la teoría. Su propósito consiste en "reconstruir" la realidad, tal y como la observan los actores del sistema social previamente definido" (Hernández Sampieri, R., Fernández Collado C. y Baptista L., 2003).

En este sentido, la técnica preponderante fue el análisis crítico y comparativo de la legislación anterior, así como de la actual y de la doctrina habida al respecto.

Según sus objetivos intrínsecos, se trata de un trabajo de tipo descriptivo, ya que se realizó un detallado análisis de las distintas normativas que receptan las funciones de responsabilidad civil en la Argentina.

${ }^{1}$ Haciendo hincapié en esta última figura jurídica. 
En cuanto a su finalidad extrínseca, es una investigación pura, ya que no existe una posibilidad inmediata de aplicación relacionada a una solución de un problema práctico. Por otra parte, se trata de un estudio de tipo bibliográfico, no previéndose la realización de trabajo de campo al efecto.

En cuanto a su temporalización es un trabajo longitudinal, ya que se analiza la evolución que han tenido en el tiempo las funciones de la responsabilidad civil, desde el Código Civil de Vélez Sarsfield hasta el estado de la legislación actual en el CCCN.

\section{3.- LA FUNCIÓN COMPENSATORIA COMO PARADIGMA DE LA RESPONSABILIDAD CIVIL EN EL CÓDIGO DE VÉLEZ SARSFIELD}

La función de la responsabilidad civil en el Derecho argentino, en su concepción original ha sido eminentemente compensatoria o resarcitoria, ya que siempre tuvo una tendencia a borrar las consecuencias del hecho dañoso, sin exceder el límite del daño efectivamente sufrido.

Destacamos la sustantividad de la función compensatoria ya que, bajo el régimen del Código Civil de Vélez Sarsfield, había autores que explicaban: "la responsabilidad civil tiene sus únicas y genuinas raíces justificativas en los principios aristotélicos de justicia conmutativa” (Bueres, A. J. y Picasso, S. 2011).

Trigo Represas y Lopez Mesa (2004) afirmaban, al diferenciar la responsabilidad civil de la penal, que "la medida de la reparación no se determina en función de la culpabilidad del autor del daño, sino de la medida de éste, sin perjuicio de lo cual, cuando se tratare de daños inferidos dolosamente o en forma alevosa, pueda servir esta circunstancia para incrementar la indemnización, aunque nunca más allá del daño sufrido”.

En un mismo sentido se ha dicho que “...como regla, el perjuicio (material o moral) sufrido por el damnificado constituye el límite más allá del cual no es posible pasar, so riesgo de convertir al daño en una fuente de lucro para el dañado y de correlativa expoliación para el responsable" (Pizarro, R. Y Vallespinos, C., 1999).

Es de hacer notar que la función resarcitoria de la responsabilidad civil fue un paradigma ${ }^{2}$ del Derecho Privado patrimonial de casi todos los países de tradición Continental - Romanista. ${ }^{3}$

En efecto, no resulta extraño que en el Código decimonónico de Vélez esto fuera así, atento las realidades que estaba destinado a regular. El codificador nunca hubiera podido imaginar los daños masivos que la evolución tecnológica era pasible de provocar, ni la magnitud de los riesgos a los que la humanidad podría llegar a estar expuesta.

Es que en el mundo actual se presentan nuevos problemas sociales que requieren de soluciones legales distintas a las del Derecho clásico, cuestiones tales como las que destacaba

\footnotetext{
${ }^{2} \mathrm{~A}$ tal efecto, se entiende por paradigma a aquellas "realizaciones universalmente reconocidas que, durante cierto tiempo, proporcionan modelos de problemas y soluciones a una comunidad científica" (Khun, T., 1996).

${ }^{3}$ Excepción hecha al Código Civil de Quebec.
} 
Bustamante Alsina (1994) hace más de una década: “...entre ellos los más acuciantes como las invasiones a la intimidad privada y ataques al honor y la reputación por abusos en el ejercicio de la libertad de prensa, la llamada "piratería" contra la propiedad industrial y los derechos intelectuales; los daños al medioambiente por contaminación del aire, del agua y sonora por ruidos excesivos, también el afán de lucro desmedido que mueve en muchos casos la actividad económica en la producción de bienes, sobre todo de consumos superfluos incentivados por una publicidad perversa; la elaboración de productos defectuosos que atentan contra la salud y la vida de los usuarios y consumidores, lanzados a la circulación sin el debido control de calidad y sin la observancia de los debidos métodos de conservación y suministro".

Ya con la reforma de la Ley 17711 se contemplaron algunos institutos ${ }^{4}$ como la acción de daño temido ${ }^{5}$ y las inmisiones inmateriales ${ }^{6}$, que avizoraban la incorporación de la función preventiva de la responsabilidad civil, así como también la Ley 21173 que incorporó al Código Civil el art. 1071 (bis) sobre invasión a la intimidad7, entre otros regulados por leyes especiales.

Así las cosas, la evolución de la vida social requirió la incorporación de otras funciones a la responsabilidad civil para evitar la producción de los daños, junto con la tradicional de compensación o reparación.

\section{4.- OTRAS FUNCIONES DE LA RESPONSABILIDAD CIVIL}

Siguiendo la evolución que han tenido las funciones de la responsabilidad civil en el Derecho Privado patrimonial argentino, la doctrina ${ }^{8}$ ha puntualizado la existencia de otras funciones además de la compensatoria, aún bajo la vigencia del Código Civil de Vélez Sarsfield, como ser la función preventiva y a la sancionatoria o punitiva.

En cuanto a la función preventiva, resulta importante distinguir aquella que previene antes del hecho, evitando que se produzcan daños, de aquella prevención ex post facto; en este caso, “...se supone que hay una condena a pagar y que ésta ha de producir un efecto disuasorio o, en todo caso, que ha de ser un incentivo importante a efectos de que el daño no se vuelva a

\footnotetext{
${ }^{4}$ Se hace referencia aquí a instituciones con finalidad preventiva en la esfera del Derecho privado patrimonial.

${ }^{5}$ Art. 2449 del Cód. Civil (hoy derogado): "Quien tema que de un edificio o de otra cosa derive un daño a sus bienes puede denunciar ese hecho al juez a fin de que se adopten las oportunas medidas cautelares".

${ }^{6}$ Art. 2618 del Cód. Civil (hoy derogado): "Las molestias que ocasionen el humo, calor olores, luminosidad, ruidos, vibraciones o daños similares por el ejercicio de actividades en inmuebles vecinos, no deben exceder la normal tolerancia teniendo en cuenta las condiciones del lugar y aunque mediare autorización administrativa para aquellas.

Según las circunstancias del caso los jueces pueden disponer la indemnización de los daños o la cesación de las molestias.

En la aplicación de esta disposición el juez debe contemporizar las exigencias de la producción y respeto debido al uso regular de la propiedad, asimismo tendrá en cuenta la prioridad en el uso".

${ }^{7}$ Expresaba este artículo: "El que arbitrariamente se entrometiere en la vida ajena, publicando retratos, difundiendo correspondencia, mortificando a otro en sus costumbres o sentimientos, o perturbando de cualquier modo su intimidad, y el hecho no fuere un delito penal, será obligado a cesar en tales actividades, si antes no hubieren cesado, y a pagar una indemnización que fijará equitativamente el juez, de acuerdo con las circunstancias; además podrá este, a pedido del agraviado, ordenar la publicación de la sentencia en un diario o periódico del lugar, si esta medida fuese procedente para una adecuada reparación".

${ }^{8}$ Autores como Pizarro, R. y Vallespinos, C., (1999), Rivera, J. (2004), entre otros.
} 
producir, para lo cual se han de adoptar las precauciones correspondientes... se cree que una sentencia que impone la obligación de indemnizar actúa sobre la sociedad para desincentivar de causar daños a sus integrantes y también percute sobre el sujeto que está obligado a soportar la condena” (Bueres, A. J. y Picasso, S. 2011), tal como ocurre en el Derecho Penal con la prevención general -para la sociedad- y especial -para el responsable civil-.

Como explica Vázquez Ferreyra, R. (2011), "hoy la responsabilidad civil ha sido ampliada por el Derecho de Daños, y en esa ampliación juega un rol fundamental la prevención de daños. Es decir que el Derecho ya no se conforma con la reparación de los daños injustamente causados, sino que va más allá, y donde le es factible, busca la propia evitación del perjuicio".

$\mathrm{O}$, al decir de Leandro Vergara (2011), "la prevención es una función o tarea destinada a evitar que ocurran los daños. Es necesario nutrir al Derecho de la Responsabilidad Civil, sin distorsionar su funcionamiento, con elementos y criterios que validen teorías en donde se privilegie la prevención".

En cuanto a la función punitiva, "subsiste una cierta creencia que nos habla del castigo al culpable. Se trata de una creencia que se apoya en la justicia retributiva de castigar al culpable. El castigo de hacerle pagar lo que su culpa ocasionó. Es un reproche de corte valorativo que deposita, de alguna manera, la realización de una justicia castigando al culpable, haciéndole pagar lo que ha hecho; en última instancia, dándole su merecida retribución” (Vergara, L., 2011).

Y más adelante expresaba el citado autor: "Al sistema de responsabilidad civil le importa más la función compensatoria... sin perjuicio de que al sujeto condenado al pago de los daños le resulte muy oneroso, y viva como un castigo el hecho de asumir el pago de varios rubros adicionales al daño ocasionado como son las costas y gastos del juicio”.

La función punitiva de la responsabilidad civil radica en castigar conductas de cierta gravedad para evitar su reiteración en el futuro, fijándose su monto con fundamento en la gravedad de la intención y no en el daño efectivamente causado.

Es de hacer notar que, "en nuestro entorno cultural es un lugar común excluir la finalidad punitiva de la responsabilidad civil” (Prevot, J. M., 2011).

Autores como Bueres y Picasso (2011) niegan la existencia de la función punitiva de la responsabilidad civil y, más aun, en el Derecho de Daños, reconociendo que, aunque materialmente las multas y las indemnizaciones pueden asimilarse -en ambos casos se cumple con la entrega de una suma de dinero-, su diferencia estriba en la finalidad de la sanción -castigar al incumplidor en el caso de la pena y en la indemnización resarcir el daño, procurando volver las cosas al estado anterior a su producción-.

En conclusión, sancionar al culpable y prevenir los daños no eran funciones de la responsabilidad civil, salvo disposición legal ${ }^{9} \mathrm{o}$ contractual expresa ${ }^{10}$, bajo el sistema de responsabilidad anterior a la entrada en vigencia del CCCN. La función de dicha responsabilidad era fundamentalmente compensatoria, pues nunca se graduaría más allá del daño sufrido por la víctima.

\footnotetext{
${ }^{9}$ Caso de los daños punitivos incorporados por la ley 26361 o de las astreintes.

${ }^{10}$ Tales como la cláusula penal o los intereses punitorios.
} 


\section{5.- LA INCORPORACIÓN DE INSTITUTOS EN OTROS MICROSISTEMAS}

Siguiendo el relato de la evolución que han tenido las funciones de la responsabilidad civil es de hacer notar que la misma se ha visto impactada por la inclusión de institutos trascendentes en algunos microsistemas del Derecho Civil, tales como el Derecho Ambiental o el Derecho de Consumo. Se hace referencia a las figuras de los principios de prevención y precautorio y a los daños punitivos, respectivamente, a los que se menciona a continuación.

\section{1.- LOS PRINCIPIOS DE PREVENCIÓN Y PRECAUTORIO EN EL DERECHO AMBIENTAL ${ }^{11}$}

La ley General del Ambiente $\mathrm{N}^{0} 25675$ establece el principio de prevención en el tercer párrafo del art. $3^{\circ}$, de la siguiente manera: "Las causas y las fuentes de los problemas ambientales se atenderán en forma prioritaria e integrada, tratando de prevenir los efectos negativos que sobre el ambiente se pueden producir".

$\mathrm{El}$ art. $2^{\mathrm{O}}$ identifica entre los objetivos de la política ambiental nacional los siguientes: “...g) Prevenir los efectos nocivos o peligrosos que las actividades antrópicas generan sobre el ambiente para posibilitar la sustentabilidad ecológica, económica y social del desarrollo;... k) Establecer procedimientos y mecanismos adecuados para la minimización de riesgos ambientales, para la prevención y mitigación de emergencias ambientales y para la recomposición de los daños causados por la contaminación ambiental”.

Este principio se complementa con el principio precautorio establecido en el párrafo cuarto del art. $4^{\circ}$ de la mencionada Ley, que expresa: “Cuando haya peligro de daño grave o irreversible la ausencia de información o certeza científica no deberá utilizarse como razón para postergar la adopción de medidas eficaces, en función de los costos, para impedir la degradación del medio ambiente”.

De lo expuesto se puede advertir que el principio de prevención tiende a la evitación de un daño futuro, pero inminente y cierto. Por su parte, el principio precautorio está destinado a impedir la creación de un riesgo con efectos todavía desconocidos e imprevisibles, en función de la evolución científica y tecnológica que puede exteriorizar perjuicios antes desconocidos.

Se debe tener en cuenta, en relación al daño ambiental, que la prevención resulta una finalidad suprema, ya que éste tiene la potencialidad de producirse en bienes que le pertenecen a la humanidad y que son de imposible o muy dificultosa reparación.

\footnotetext{
${ }^{11}$ Se aclara que en el presente sólo se hace una somera y estrecha síntesis acerca de la concepción de estos institutos, por razones de brevedad y debido a que no forman parte del objeto del presente análisis.
} 


\section{2.- LOS DAÑOS PUNITIVOS EN EL DERECHO DE CONSUMO}

La ley 26361 introdujo a la Ley 24240 la figura de los daños punitivos ${ }^{12}$. Se trata de multas civiles que se imponen al autor de una conducta dañosa, con la finalidad ejemplificadora de sancionar al autor de dicho daño, así como de prevención general y especial de la ocurrencia de futuros menoscabos en los derechos de terceros, por hechos similares, al resultar disuasoria.

$\mathrm{Al}$ respecto, dispone el art. 52 bis de la LDC: "Daño Punitivo. Al proveedor que no cumpla sus obligaciones legales o contractuales con el consumidor, a instancia del damnificado, el juez podrá aplicar una multa civil a favor del consumidor, la que se graduará en función de la gravedad del hecho y demás circunstancias del caso, independientemente de otras indemnizaciones que correspondan. Cuando más de un proveedor sea responsable del incumplimiento responderán todos solidariamente ante el consumidor, sin perjuicio de las acciones de regreso que les correspondan. La multa civil que se imponga no podrá superar el máximo de la sanción de multa prevista en el artículo 47, inciso b) de esta ley".

Esta norma ha sido fuertemente criticada por la doctrina nacional por diversos factores, tales como su técnica legislativa, el factor de atribución de la responsabilidad requerido para su procedencia, el destino de la multa, la responsabilidad solidaria, el tope cuantitativo de la multa y la dificultad para articular una figura del Derecho anglosajón con la tradición Continental - Romanista de nuestro sistema de responsabilidad civil.

Pero aquí nos interesa hacer hincapié en la naturaleza sancionatoria de este instituto, como manifestación de la incorporación de la función punitiva al sistema de responsabilidad civil en el Derecho Privado argentino.

Los daños punitivos no están destinados a reparar, sino que se adicionan a las indemnizaciones compensatorias con la finalidad principal de castigar al dañador. ${ }^{13}$ Técnicamente, no constituyen un "resarcimiento, sino una institución distinta: una pena privada, que el ordenamiento jurídico admite y legitima bajo ciertas circunstancias. Una suerte de indemnización punitiva (expresión que luce cuando menos contradictoria) o, más precisamente, una pena civil orientada a sancionar, a punir antes que a reparar" (Pizarro, R. y Vallespinos, C., op. cit.).

La Cámara Nacional de Apelaciones en lo Civil, Sala F, destacó su naturaleza diciendo que: "Este instituto tiene un propósito netamente sancionatorio del daño que resulta intolerable, siendo su finalidad punir graves inconductas, y prevenir el acaecimiento de hechos similares”.

Con los daños punitivos se persigue "una tríada de funciones: a) punir graves inconductas; b) hacer desaparecer los beneficios injustamente obtenidos a través de la actividad dañosa,

\footnotetext{
${ }^{12}$ La doctrina critica la denominación "daños punitivos" atento a que la misma responde a una traducción literal, pero imprecisa, del precedente en el idioma inglés punitive damages donde la palabra damage tiene dos significados relacionados, pero distintos. Por un lado define al perjuicio sufrido por el damnificado como consecuencia de la acción de quien resulte responsable y, por el otro, a la indemnización debida a la víctima por el autor de la conducta ilícita. Aun teniendo en cuenta estas críticas, se utilizará el término empleado por la ley para referir a la figura sub examine.

${ }^{13}$ Algunos autores como Leandro Vergara piensan que la principal finalidad de los daños punitivos es preventiva y no sancionatoria. Esta afirmación debe ser tomada con cautela, ya que la potencialidad preventiva de la figura estará íntimamente relacionada con la cuantía de la multa en relación al patrimonio del dañador, a la intención que tuvo el mismo y a la posibilidad de que con los daños provocados, el proveedor se siga enriqueciendo a costa de otros consumidores. En la Argentina, los tribunales han venido aplicando tímidamente la figura, con montos a veces irrisorios, impidiendo que se consiga la finalidad disuasiva con la que fue pergeñada la figura.
} 
y c) prevenir o evitar el acaecimiento de hechos lesivos similares al que se impusiera punición" (Prevot, J. M., 2011).

Dado el carácter sancionatorio de los daños punitivos, quien los imponga deberá realizar una interpretación restrictiva para su aplicación, excepcional, debiendo estar fundada, respetando las garantías propias del sistema represivo, de acuerdo a los principios del Debido Proceso establecido en el art. 18 de la Constitución Nacional y concordantes en los Tratados Internacionales con jerarquía constitucional (art. 75, inc. $22 \mathrm{CN}$ ).

\section{6.- LA POLIFUNCIONALIDAD EN EL ANTEPROYECTO DE REFORMA Y SUS FUNDAMENTOS}

El Anteproyecto de Unificación de los Códigos Civil y Comercial presentado en el año 2012 trataba el tema en el Libro Tercero: De los derechos personales, Título V: De otras fuentes de las Obligaciones, Capítulo I: Responsabilidad Civil, Sección $1^{\mathrm{a}}$ Disposiciones generales y Sección $2^{\text {a }}$ De la función preventiva y la sanción pecuniaria disuasiva.

Rezaba el artículo 1708 "Funciones de la responsabilidad. Las disposiciones de este Título son aplicables a la prevención del daño, a su reparación, y a los supuestos en que sea admisible la sanción pecuniaria disuasiva".

Tal como estaba proyectado se hubiera producido un cambio en el sistema de responsabilidad civil donde la principal función hubiera sido la prevención, luego la reparación y, excepcionalmente, la sanción.

En los Fundamentos del proyecto, la Comisión Redactora expresaba: "tanto en el derecho comparado como en nuestro país existen discusiones doctrinales acerca de si la prevención y la punición integran o no la noción de responsabilidad; es necesario, pues, que la ley resuelva la controversia. Por ello, el primer artículo señala que las normas son aplicables a los tres supuestos, y los subsiguientes contemplan la prevención, la reparación y la sanción pecuniaria disuasiva” (Lorenzetti, R., Highton De Nolasco, E. y Kemelmajer De Carlucci, A., 2012).

En tal sentido, el art. 1714 del Proyecto regulaba a los daños punitivos bajo el nombre de "sanción pecuniaria disuasiva"14"; el mismo establecía: "El juez tiene atribuciones para aplicar, a petición de parte, con fines disuasivos, una sanción pecuniaria a quien actúa con grave menosprecio hacia los derechos de incidencia colectiva. Pueden peticionarla los legitimados para defender dichos derechos. Su monto se fija prudencialmente, tomando en consideración las circunstancias del caso, en especial la gravedad de la conducta del sancionado, su repercusión social, los beneficios que obtuvo o pudo obtener, los efectos disuasivos de la medida, el patrimonio del dañador, y la posible existencia de otras sanciones penales o administrativas.

La sanción tiene el destino que le asigne el juez por resolución fundada”.

${ }^{14}$ Denominación que se estima más correcta. 
Es decir que se dejaba un amplísimo arbitrio al juez para decidir la aplicación, para fijar el monto con unas pautas genéricas tales como las circunstancias del caso, en especial la gravedad de la conducta del sancionado, su repercusión social, los beneficios que obtuvo o pudo obtener, los efectos disuasivos de la medida, el patrimonio del dañador, y la posible existencia de otras sanciones penales o administrativas, permitiéndole, asimismo, asignar su destino por resolución fundada.

En relación a la sanción pecuniaria disuasiva, en los Fundamentos se explicaba sus supuestos de procedencia de la siguiente manera:

1. Derechos individuales en las relaciones de consumo: es aplicable el régimen especial de la Ley de Defensa del Consumidor que prevé este dispositivo. Aunque se proyectaba una reforma al art. 52 bis en una redacción prácticamente idéntica a la proyectada en el art. 1714 ya comentado.

2. Derechos de incidencia colectiva: se aplica conforme a la norma proyectada.

3. Derechos individuales que no están dentro de una relación de consumo: no se aplica.

4. Derechos individuales afectados como consecuencia de la lesión a un bien colectivo: no se aplica.

En otro orden, reseñaban los fundamentos: “a) no hay experiencia en nuestro país sobre la sanción pecuniaria y la propia ley de defensa de los consumidores no ha generado jurisprudencia sostenida en este aspecto. Por lo tanto es mejor diseñar una norma que abra la puerta a este instituto con mayores especificaciones que las existentes en la ley especial y esperar su desarrollo. Siempre habrá tiempo para ampliar a los otros supuestos mediante leyes especiales, pero no se puede avanzar a ciegas en materia de política legislativa. b) el campo de aplicación es muy amplio y significativo, de modo que se permite un desarrollo del instituto mediante la jurisprudencia y doctrina que va a permitir definir con mayor claridad sus perfiles. Es lo que ha sucedido en los países donde se ha aplicado; c) no hay buenos ejemplos sobre una regla general en un código civil; d) se ha preferido optar por un sistema de protección de bienes colectivos, en los que el peligro es mayor por la denominada "tragedia de los bienes comunes", es decir, no hay incentivos individuales para su tutela" (Lorenzetti, R., Highton De Nolasco, E. y Kemelmajer De Carlucci, A., 2012).

También se reseñaban en los fundamentos los caracteres del instituto: el destino de la “indemnización”; el seguro, opinando la Comisión que el tema de la asegurabilidad de los daños punitivos, "es mejor que sea una ley especial la que defina el tema en el futuro, ya que hoy no puede asegurarse".

Asimismo, se regulaba en el art. 1715 las cuestiones relativas a la punición excesiva, hoy desdobladas en los arts. 1714 y 1715 del CCCN.

Esta previsión era una aplicación explícita del principio de equidad, que actuaba como contrapeso de eventuales excesos en la aplicación y cuantificación de la sanción disuasiva. Esto 
se daba ya que el artículo sub examine determinaba que si por causa de un mismo hecho nocivo concurren varias condenaciones de distinta naturaleza (administrativas, penales o civiles) que provocan una punición irrazonable o excesiva, el juez debía computar el resultado de esa acumulación y, en tal caso, podía reducir la cuantía o dejar sin efecto, total o parcialmente, la sanción pecuniaria para morigerar la punición desproporcionada, resultante del rigorismo de la aplicación de la ley.

Habiéndose suprimido la figura de la sanción pecuniaria disuasiva, la normativa de los arts. 1714 y 1715 del CCCN adquieren un significado distinto, al que se hará referencia más adelante.

\section{7.- LA SALIDA DE LA SANCIÓN PECUNIARIA DISUASIVA}

La función punitiva excepcional, prevista tanto en el Anteproyecto de la Comisión Reformadora como en el Proyecto enviado al Congreso por el Poder Ejecutivo, fue excluida del texto finalmente aprobado en el CCCN mediante la decisión de la Comisión Bicameral designada para su tratamiento.

Los fundamentos para dicha supresión fueron los siguientes: "[s]e elimina el instituto de la sanción pecuniaria disuasiva del Proyecto, con el fin de que la autoridad de aplicación mantenga sus potestades, inhibiendo a la autoridad jurisdiccional de resolver estas cuestiones. Sin embargo se mantiene el artículo 1715 sobre punición excesiva, con su texto desdoblado, por entender que su campo de aplicación se extiende más allá de la supresión mencionada pues en su ámbito quedan comprendidas otras sanciones civiles, como las conminatorias reguladas en el artículo 804 y la especial en materia de daño punitivo contemplada en el artículo 52 bis en la ley 24.240 y su modificatoria. Asimismo, se adecua la denominación de la Sección $2^{\text {a }}$ la que pertenece el artículo suprimido con la finalidad de comprender a la función preventiva y al supuesto de punición excesiva. También, se suprime el inciso h, del artículo 930 relativo a las obligaciones no compensables entre las que se encuentra, en la versión de origen, la obligación de pagar una sanción pecuniaria disuasiva. Con la misma finalidad se modifica la redacción del artículo 1708, relativo a las funciones de la responsabilidad, suprimiendo la referencia a la sanción pecuniaria disuasiva".

Se considera que estas explicaciones resultan cuestionables atento a que la aplicación de los daños punitivos -sanción pecuniaria disuasiva, en el texto proyectado- nunca fue una potestad conferida a la autoridad administrativa, sino una aplicación de la función jurisdiccional. Posiblemente se haya confundido a esta figura con otra introducida en la LDC en la misma reforma que los daños punitivos por la Ley 26361, como el daño directo previsto por el art. 40 bis de la LDC que sí corresponde a la autoridad administrativa. 
Se trata de una decisión de política legislativa al analizar la incorporación de una figura proveniente de una tradición jurídica extraña a la nacional, con un alcance más amplio que el establecido en la LDC -para todos los derechos de incidencia colectiva y no sólo los del consumidor- y que dicha inclusión ya había sido fuertemente criticada por la doctrina especializada.

En tal sentido se ha dicho que "el juicio de adaptabilidad a la cultura jurídica propia es una función central de los jueces; de otra forma el proceso de importación de instituciones -en el caso, no ya de su diseño (que es un problema del legislador), sino de la fijación de pautas de funcionamiento- se realizaría de manera acrítica y podría desestabilizar el sistema introduciendo elementos que le son extraños e incompatibles con su propia necesidad" (Sozzo, G., 2013).

Lo cierto es que el recorte de esta figura, manteniendo los arts. 1714 y 1715 actuales, resulta innecesaria y, cuando menos, desprolija.

Como ya se ha adelantado, no se coincide con la opinión de destacados autores que sostienen que el mantenimiento de estos artículos implica la virtualidad de la sanción pecuniaria disuasiva -y de la función punitiva en el $\mathrm{CCCN}-$, ya que la misma fue expresamente excluida por decisión del Poder Legislativo. Pero resulta estéril su mantenimiento debido a que la aplicación de otras sanciones contractuales (como los intereses excesivos) o legales (como las astreintes) tienen su propias normas de morigeración, así como también los daños punitivos tienen un tope cuantitativo, tal el establecido por el art. 47 de la LDC, según lo dispuesto por el art. 52 bis de esa misma norma legal.

\section{8.- LAS FUNCIONES DE LA RESPONSABILIDAD CIVIL EN EL CÓDIGO CIVIL Y COMERCIAL DE LA NACIÓN}

El texto definitivo del CCCN mantuvo como funciones de la responsabilidad ci-vil la preventiva y la compensatoria o reparatoria, eliminando la factibilidad de implementación de la sanción pecuniaria disuasiva para los casos de vulneración de los derechos de incidencia colectiva y subsistiendo, por otra parte, vigente la norma del art. 52 bis de la LDC que regula la figura de los daños punitivos. ${ }^{15}$

En efecto, establece el art. 1708 del Código Civil y Comercial de la República Argentina: "Funciones de la responsabilidad. Las disposiciones de este Título son aplicables a la prevención del daño y a su reparación”.

Respecto a la función preventiva, se establece el deber general de prevenir, así como también se regula la acción preventiva.

${ }^{15}$ En la redacción incorporada por la Ley 26361. 
En cuanto a la función resarcitoria, el CCCN prevé el deber de reparar, definiendo, a su vez, la antijuricidad y determina los eximentes de responsabilidad; establece los factores de atribución de la responsabilidad, dejando el factor culpa como residual y refuerza las cuestiones que la doctrina y la jurisprudencia habían perfilado bajo la vigencia del Código de Vélez, otorgando amplias facultades a los jueces a la hora de determinar todas las cuestiones relativas a la responsabilidad.

Además, el Código también regula el supuesto de la punición excesiva, estableciendo en el art. 1714 que "Si la aplicación de condenaciones pecuniarias administrativas, penales o civiles respecto de un hecho provoca una punición irrazonable o excesiva, el juez debe computarla a los fines de fijar prudencialmente su monto"16. Asimismo, en el artículo siguiente, se faculta al magistrado a dejar total o parcialmente sin efecto tales condenaciones.

Al decir de Matilde Zavala De González (2015), la "multiplicidad funcional constituye materia irrenunciable del derecho de daños, cuyo sistema no sería completo ni satisfactorio sin esas proyecciones, que son autónomas pero se entrelazan y refuerzan recíprocamente".

En síntesis, en la redacción vigente el CCCN diseña un sistema de responsabilidad civil en que se perfila a la prevención como nueva función explícita de la responsabilidad civil; si el daño ya se produjo, se mantiene la compensación, permaneciendo la precaución y la punición como funciones propias de la responsabilidad en el Derecho Ambiental y en el Derecho de Consumo, respectivamente.

\section{1.- LA PREVENCIÓN COMO FUNCIÓN DEL SISTEMA Y EL DEBER DE PREVENIR}

En función de la evolución normativa reseñada podemos decir que, en el Derecho Privado argentino vigente, la función preventiva pasó a ser una función explícita, integrada al sistema y con jerarquía constitucional. ${ }^{17}$

Este cambio valorativo obliga a todos los operadores jurídicos a reaccionar frente a un riesgo o amenaza de daño y revela la necesidad de adecuar los códigos procesales hacia la prevención; aunque el CCCN regula la función preventiva desde el punto de vista sustantivo.

El art. 1710 del CCCN consagra el deber de prevención, en los siguientes términos: "Toda persona tiene el deber, en cuanto de ella dependa, de:

a. evitar causar un daño no justificado;

b. adoptar, de buena fe y conforme a las circunstancias, las medidas razonables para evitar que se produzca un daño, o disminuir su magnitud; si tales medidas evitan o disminuyen la

\footnotetext{
${ }^{16}$ Algunos autores consideran que la subsistencia de este artículo implica la plena vigencia, en el ordenamiento iusprivatista, de la función punitiva mediante la sanción pecuniaria disuasiva. Tal es el caso, por ejemplo, de Echevesti, R. (2015), que expresa: “Pero además de estas funciones, surge categóricamente del articulado que se recepta la función PUNITIVA, bajo la denominación de condenaciones pecuniarias civiles (sic. Art. 1714)... Tras su paso por el derecho del consumidor; es recobrada ahora para la esfera de nuestro derecho civil"... "Es por ello que, consideramos que la figura no solo está contemplada, sino que lo está con una mayor amplitud que la que se le hubiera dado en el proyecto, en el cual se contem-plaba solo para el supuesto de derechos de incidencia colectiva".

No se coincide con esta afirmación dado que la figura de la sanción pecuniaria disuasiva fue expresamente excluida por el Congreso de la Nación al tratar la aprobación del CCCN mediante la Comisión Bicameral designada al efecto y que la punición excesiva puede resultar de otras sanciones tales como cláusulas penales, intereses punitorios, astreintes u otras multas penales o administrativas.

${ }^{17}$ Así lo expresan Monjo, S. y Argañaraz, M. (2015).
} 
magnitud de un daño del cual un tercero sería responsable, tiene derecho a que éste le reembolse el valor de los gastos en que incurrió, conforme a las reglas del enriquecimiento sin causa;

c. no agravar el daño, si ya se produjo".

Según el texto de la norma, toda persona debe adoptar las conductas u omisiones conducentes para impedir la producción o agravamiento del daño, estando este deber -de prevención- condicionado a las posibilidades de evitar el perjuicio que tenga quien pueda asegurar dicha prevención.

Estas personas deben evitar causar un daño no justificado, adoptar de buena fe y conforme las circunstancias del caso, las medidas razonables para evitar que se produzca el daño o para disminuir su magnitud -actuando antes que éste se produzca-, y no agravar el daño -si ya se produjo-. Será el juzgador, quien determinará si en esas circunstancias era razonable exigir al sujeto determinado un actuar preventivo.

"Las conductas aludidas tienden a inducir a los individuos y a las empresas a rea-lizar comportamientos adecuados para reducir la probabilidad o la gravedad de los daños previsibles. De esta manera se minimiza el coste social de los daños mientras se maximiza el bienestar de la sociedad” (Monjo, S. y Argañaraz, M., 2015).

En definitiva, el principio de prevención constituye un mandato indeterminado que deberá concretarse en cada caso, según sus singularidades.

Resulta importante comprender el significado de la reforma, en el sentido que expresa Lorenzetti (2015): "Se contempla expresamente la función preventiva de la responsabilidad civil, estableciéndose los requisitos, los deberes para evitar causar o agravar el daño futuro o el daño en curso. La omisión de ejecutar el deber de prevención o la realización de la conducta de abstención constituye un ilícito extracontractual”, todo esto según expresa regulación legal.

\section{2.- LA ACCIÓN PREVENTIVA}

Esta acción está prevista en el art. 1711 del CCCN que establece: "Acción preventiva. La acción preventiva procede cuando una acción u omisión antijurídica hace previsible la producción de un daño, su continuación o agravamiento. No es exigible la concurrencia de ningún factor de atribución".

Esta norma resulta trascendente ya que efectiviza el deber de prevenir y operativiza la función preventiva, a través de una herramienta jurídica que excita la función jurisdiccional, para detener el curso dañoso.

Este instrumento procesal, también conocido como tutela inhibitoria, tiene como finalidad evitar que se produzca un daño (si es que existe una amenaza de que acaezca), proceder al cese del mismo o impedir su agravamiento (si este ya se produjo o sigue en curso).

"Constituye una protección judicial de urgencia sustantiva, y no cautelar y cuyos presupuestos son un comportamiento lesivo, un daño injusto y una relación de causalidad adecuada entre dicho comportamiento y el daño causado" (Lorenzetti, 2015). 
Esta tutela resulta de vital trascendencia ya que en los procesos de imperiosa necesidad -urgentes- lo normal era recurrir a medidas cautelares relacionadas a un juicio principal, a las que se accedía en diversos momentos del litigio, pero de manera provisional, resultando necesario resolver las pretensiones urgentes con medidas definitivas. Con esta finalidad surgieron las medidas autosatisfactivas y las sentencias anticipatorias (formas estas en que se manifiesta la comentada acción preventiva).

Se establecen los siguientes requisitos para la procedencia de la acción bajo examen:

1) Una conducta antijurídica: acción u omisión de carácter ilícito que hace previsible la producción del daño, su agravamiento o continuación.

2) Interés legítimo del peticionante: ya sea individual, individual homogéneo o colectivo, patrimonial o extrapatrimonial.

3) Posibilidad concreta: de acción u omisión para evitar el daño o sus efectos.

4) Adecuada relación de causalidad: entre la conducta debida y el resultado probable, es decir, con el perjuicio esperable según el curso normal de las cosas (arts. 1725, 1726, 1727 del CCCN).

También resulta importante la mención que hace el artículo, en su parte final, acerca de la innecesaridad de concurrencia de factores de atribución de la responsabilidad, tanto objetivos como subjetivos, ya que esto facilitará la actividad probatoria en un proceso que, por su naturaleza, deberá revestir carácter sumarísimo.

En cuanto a la legitimación, establece el art. 1712 que se encuentran legitimados para reclamar mediante la acción preventiva quienes acrediten un interés razonable en la prevención del daño.

Resulta interesante la definición de este interés razonable ya que el mismo excedería la noción de damnificados directos e indirectos, lo que resulta lógico por la inclusión expresa a la protección de los derechos de incidencia colectiva ${ }^{18}$. "Se presume el interés de quienes sufrieron o pueden sufrir un daño individual o colectivo en su carácter de víctimas actuales o potenciales; los otros damnificados indirectos deben demostrar, aun sumariamente, su interés" (Lorenzetti, 2015).

Se trata de un interés definido por negación, aquél que no se encuentra en contra del ordenamiento jurídico.

Por último, en relación a esta temática, el art. 1713 establece cuestiones relativas a la sentencia que dirime esta acción, de la siguiente manera: "La sentencia que admite la acción preventiva debe disponer, a pedido de parte o de oficio, en forma definitiva o provisoria, obligaciones de dar, hacer o no hacer, según corresponda; debe ponderar los criterios de menor restricción posible y de medio más idóneo para asegurar la eficacia en la obtención de la finalidad".

En relación a esta decisión judicial se pueden disponer medidas provisorias o definitivas o disponer medidas transitorias (como la tutela inhibitoria), con una amplísima libertad juris- 
diccional en cuanto a su contenido ${ }^{19}$, además puede modificar la pretensión y adecuarla a las circunstancias del caso.

"El objeto de la sentencia es impedir la producción o agravamiento del daño por lo que las medidas a disponer serán de lo más variadas de acuerdo a las circunstancias y consistirán en detener o frenar un hecho, hacer cesar la realización de una actividad, asegurar o modificar una situación de hecho o de derecho, imponer obligaciones de hacer (v. gr., asegurar una pared con riesgo de caída a la vía pública) o de no hacer (v. gr., paralizar una construcción) o de dar (vg., entregar dinero para efectuar la reparación)" (Lorenzetti, 2015).

El decisorio de la sentencia debe resultar de un juicio de ponderación, atendiendo, según el texto expreso de la norma, a la menor restricción posible del derecho limitado y a la idoneidad de la restricción con relación a la obtención de la eficacia del resultado. Se debe siempre comparar la entidad y atendibilidad de los derechos controvertidos, debiendo primar los extrapatrimoniales sobre los patrimoniales y los derechos de incidencia colectiva sobre los individuales, así como también, principalmente, la tutela de la persona a la del patrimonio.

Esta norma deberá ser complementada con la regulación procesal local, pero fija un "piso" sustancial, en aras a brindar seguridad jurídica al principio de prevención como función principal de la responsabilidad civil, manteniendo plena vigencia las disposiciones de las leyes especiales.

\section{3.- LA COMPENSACIÓN DEL DAÑO SUFRIDO}

En la Sección dedicada a la regulación de la función resarcitoria se legislan sus presupuestos: antijuridicidad, factores de atribución y nexo causal, para luego dedicar la Sección siguiente al daño, en especial.

Una de las principales innovaciones en la materia está dada por la unificación del régimen de responsabilidad contractual y extracontractual, según establece el art. 1716: "Deber de reparar. La violación del deber de no dañar a otro, o el incumplimiento de una obligación, da lugar a la reparación del daño causado, conforme con las disposiciones de este Código".

Como aclara Lorenzetti (2015), "cualquiera sea la fuente del deber de reparar el daño (la violación del deber general de no dañar, o el incumplimiento de una obligación), la responsabilidad se rige, en principio, por las mismas reglas. Concordantemente,... las normas que integran el presente capítulo (arts. 1708 a 1780) se aplican indistintamente a la responsabilidad contractual y la extracontractual".

Sin embargo, subsisten varias excepciones, fundadas en la especificidad que reviste el incumplimiento del deber de no dañar, el incumplimiento obligacional y la necesidad de respetar las cláusulas dispuestas -en función de la autonomía de la voluntad- por las partes en los contratos negociados.

Otra novedad legislativa está incluida en el artículo que regula al consentimiento del damnificado. En tal sentido, establece el art. 1720: “Sin perjuicio de disposiciones especiales, el con-

${ }^{19}$ Obligaciones de dar, de hacer o de no hacer. 
sentimiento libre e informado del damnificado, en la medida en que no constituya una cláusula abusiva, libera de la responsabilidad por los daños derivados de la lesión de bienes disponibles”.

En esta norma se establece un principio general según el cual, bajo ciertas condiciones (que no constituya una cláusula abusiva, que sea libre e informado y verse sobre bienes disponibles), el consentimiento de la víctima se convierte en una causal de justificación del daño.

Luego, en el artículo siguiente, se establece la necesidad de factores de atribución objetivos y subjetivos para que devenga la responsabilidad, determinando a la culpa como factor residual o de clausura.

"La culpa será un factor subjetivo relevante que, integrado adecuadamente con los factores objetivos, conformarán un sistema coherente y armónico que confiere basamento -jurídico y axiológico- al deber de responder" (Lorenzetti, 2015).

En resumida síntesis ${ }^{20}$, en el articulado relativo a la función resarcitoria el CCCN establece normas sobre el deber de reparar así como a los distintos elementos que configuran la responsabilidad: antijuricidad, factores de atribución, relación causal, dedicando la Sección siguiente a todos los pormenores del daño.

También regula los eximentes que derivan de la ruptura de tales elementos: legítima defensa, estado de necesidad y ejercicio regular de un derecho; causa ajena, hecho del damnificado o de un tercero por quien no se debe responder; consentimiento del damnificado, caso fortuito o fuerza mayor e imposibilidad de cumplimiento.

Asimismo se definen los factores de atribución subjetivos y objetivos y se legislan algunas cuestiones procesales básicas relativas a la prueba de todos estos elementos y eximentes.

\section{9.- EL NUEVO PARADIGMA DE LA POLIFUNCIONALIDAD EN EL DERECHO PRIVADO PATRIMONIAL ARGENTINO}

Ante la vigencia del CCCN, resulta necesario admitir que la responsabilidad en el Derecho argentino asume una pluralidad de funciones, centralmente preventiva y resarcitoria y periféricamente precautoria y punitiva.

Pero, tal como lo explica SOZZO (2013), la polifuncionalidad implica asumir nuevos paradigmas de sociedad, de ciencia y de Derecho. "Esto no se ha hecho; no ha existido una reflexión adecuada en este punto, como consecuencia de lo cual la coexistencia entre dispositivos proveniente de los diferentes paradigmas que subyacen a las distintas funciones no se encuentra regulada". La introducción del nuevo paradigma de la polifuncionalidad de la responsabilidad civil, “...debería propulsar la reflexión y la construcción de prácticas acordes con

\footnotetext{
${ }^{20}$ Por razones de brevedad, no se realiza un análisis pormenorizado del articulado que regula la función compensatoria de la responsabilidad civil y solamente se comentan los cambios más relevantes introducidos por el CCCN, habida cuenta que se trata de la función tradicional del sistema.
} 
la complejidad que la coexistencia de estos diferentes paradigmas implica. La clave para ello es el diálogo de fuentes" (Sozzo, G., 2013).

La coexistencia de los diferentes idearios que subyacen en cada una de las funciones de la responsabilidad civil ${ }^{21}$ en el $\mathrm{CCCN}$ puede encarar el diálogo a partir del conflicto de derechos fundamentales. "El campo de estos conflictos de derechos fundamentales podría transformarse en el campo de diálogo entre las concepciones que subyacen a cada función” (Sozzo, 2013).

El diálogo de fuentes implica la necesidad de integrar al Derecho, a la luz de la Constitución Nacional y los tratados internacionales, llevando y trayendo soluciones de los distintos microsistemas establecidos en leyes especiales, así como las normas contenidas en el CCCN. Esta tarea integradora deberá realizarse en aras a obtener la solución más justa, con toda la amplitud que las distintas concepciones acerca de la justicia le brindan a este término y bajo los paradigmas del CCCN que propenden a la humanización del Derecho y a desalentar las situaciones de abuso, favoreciendo al débil jurídico.

\section{0.- CONCLUSIONES}

En virtud de todo lo reseñado, se ha analizado y descripto la evolución habida en el sistema de Derecho Privado patrimonial argentino, a raíz de la inclusión de varias funciones de la responsabilidad civil.

Se ha relatado cómo se configuraba el paradigma de la responsabilidad compensatoria en el Código de Vélez Sarsfield, para luego señalar distintas señales de crisis que dichas soluciones comenzaban a plantear a los problemas que se venían presentando en la sociedad y que fueron receptadas en diferentes reformas parciales al articulado, como las que introdujo la Ley 17711 (acción de daño temido, inmisiones inmateriales, etc.) y la Ley 21173 (invasión a la intimidad).

Por su parte, se ha realizado una descripción de otras crisis al paradigma de la función resarcitoria que vinieron a impactar al Derecho privado patrimonial desde algunos microsistemas, como el Derecho Ambiental (mediante la operativización de los principios de prevención y precautorio) y el Derecho de Consumo (a través de la incorporación de la figura de los daños punitivos).

Esta última crisis provocó un quiebre que determinó la necesidad de una reforma legislativa integral que dotara de otras funciones a la responsabilidad civil.

Dicha modificación fue encarada por la Comisión Reformadora del CCCN a través de la regulación de una tríada de funciones para la responsabilidad civil -preventiva, resarcitoria y punitivaen el Anteproyecto de Código Civil y Comercial de la Nación. Este diseño se mantuvo en el Proyecto enviado por el Poder Ejecutivo Nacional, pero fue recortado por la Comisión Bicameral designada para su tratamiento en el Congreso de la Nación, extrayendo la función sancionatoria.

\footnotetext{
$\overline{{ }^{21} \text { El riesgo, para la función preventiva; el daño para la función resarcitoria, la incertidumbre para la función precautoria y el grave }}$ menosprecio por los derechos ajenos para la sancionatoria.
} 
De la misma manera, se ha analizado el paradigma actual de las funciones de la responsabilidad civil en el CCCN, que diseña un sistema en que se perfila a la prevención como operativización del principio alterum non laedere, de haberse producido el daño se mantiene la función compensatoria, permaneciendo la precaución y la punición como funciones propias de la responsabilidad en el Derecho Ambiental y en el Derecho de Consumo, respectivamente.

Es decir que la responsabilidad en el Derecho privado patrimonial argentino asume una pluralidad de funciones, centralmente preventiva y resarcitoria y periféricamente precautoria y punitiva.

Para mantener la plena vigencia de esta polifuncionalidad en la articulación de este sistema, para cada caso concreto, el intérprete deberá realizar un adecuado diálogo de fuentes.

En cada caso concreto, el intérprete deberá preguntarse si el daño se produjo, o no. De no haberse producido, deberá indagar si puede evitarse.

Si esta última solución es posible, deberá inquirir si se trata de un daño al medioambiente, ya que en tal situación cobrará plena vigencia el principio de prevención -y el precautorio, dependiendo de los supuestos- que tendrá que ser integrado con lo establecido en los arts. 41 y 43 de la Constitución Nacional y las normas concordantes de los tratados internacionales. Asimismo, cobraría plena vigencia la acción preventiva regulada en el $\mathrm{CCCN}$, articulada con las herramientas de la Ley General de Ambiente.

Si el daño no está relacionado con bienes ambientales también habrá de preguntarse si éste se produjo en una relación de consumo, ya que de ser así el diálogo estará dado entre los arts. 42 y 43 de la Constitución Nacional -que enfatizan el deber de prevenir-, los tratados internacionales, la LDC y la acción preventiva del CCCN.

Ahora bien, si ese daño se produjo en una relación de consumo, mediando incumplimiento de una obligación legal o contractual con grave menosprecio a los derechos de terceros por parte del proveedor, el intérprete deberá analizar también la viabilidad de la función sancionatoria, a través de la aplicación de los daños punitivos, siendo esta una excepcional potestad judicial.

Por su parte, si el daño evitable no tiene que ver con bienes ambientales ni con una relación de consumo, tiene plena vigencia el articulado relativo a la función preventiva y la punición excesiva en el CCCN.

Por otro lado, si el daño ya se produjo o no puede evitarse, éste deberá repararse, debiendo asimismo intentar de buscar soluciones integradoras con la finalidad de no agravarlo y morigerarlo.

Asimismo, la realización de este diálogo de fuentes deberá tener en cuenta la vulneración de derechos fundamentales, ya que de darse ese supuesto también sería útil dejarlo plasmado en un juicio de ponderación, debiendo comparar la entidad y atendibilidad de los derechos controvertidos, haciendo primar los extrapatrimoniales sobre los patrimoniales y los derechos de incidencia colectiva sobre los individuales, así como también, principalmente, la tutela de la persona a la del patrimonio, tratando de preservar la plena vigencia de la Ley. 
Suponer que los problemas relacionados a las funciones de la responsabilidad civil pueden afrontarse trabajando solamente con la regla expresada en el CCCN, su doctrina y la jurisprudencia recaída en casos similares o análogos decididos con anterioridad a su entrada en vigencia, ya no es aceptable hoy día.

"Los principios y valores constitucionales (incluyendo a la fuente internacional) traspasan en la actualidad todas las ramas del Derecho y por tanto exigen un trabajo muy distinto (y mucho más complejo) con los materiales jurídicos, con relación al modo tradicional aludido. Principios como el de pro homine, el de pro actione o el de favor debilis, de raigambre internacional pero receptados en nuestra Constitución, no pueden válidamente (o en todo caso, exitosamente) ser desatendidos ante un problema de la realidad que deba afrontarse, toda vez que en verdad "condicionan" el modo de encararlos en cualquier rol que desempeñe el operador jurídico" (Depetris, C., 2015).

\section{REFERENCIAS BIBLIOGRÁFICAS}

Bueres, A. J. y Picasso, S. (2011) "La función de la responsabilidad civil y los daños punitivos”. Revista de Derecho de Daños, 2011 (2). Buenos Aires: Rubinzal - Culzoni.

Bustamante Alsina, J. (1994) "Los llamados "daños punitivos" son extraños a nuestro sistema de responsabilidad civil”. Buenos Aires: LA LEY 1994 - B.

Depetris, C. (2015) "Hacia un cambio en la práctica jurídica: Notas sobre el Capítulo 1 del Título preliminar del Código Civil y Comercial”. Recuperado: 23/11/2015. Disponible en: http://www.infojus.gob.ar/carlos-emilio-depetris-hacia-cambio-practica-juridica-notassobre-capitulo-1-titulo-preliminar-codigo-civil-comercial-dacf150652-2015-06-01/123456789-oabc-defg2560-51fcanirtcod

Echevesti, R. (2015) “Código Civil y Comercial de la Nación. Diez puntos básicos en responsabilidad”. Recuperado: 03/11/2015. Disponible en:

http://www.infojus.gob.ar/rosario-echevesti-codigo-civil-comercial-nacion-diez-puntos-basicosresponsabilidad-dacf150819-2015-11-10/123456789-0abc-defg9180-51fcanirtcod

Hernández Sampieri, R., Fernández, C. y Baptista, P (2003). Metodología de la investigación. México: Mac Graw-Hill. 
Khun, T. (1996) De los paradigmas a la teoría evolucionistas. Buenos Aires: Oficina de Publicaciones C.B.C.

Lorenzzetti, R. (2012) “Presentación del Proyecto". En: PODER EJECUTIVO DE LA REPÚBLICA ARGENTINA (2012) Proyecto de Código Civil y Comercial de la Nación. Buenos Aires: La Ley.

Lorenzetti, R. Highton de Nolasco, E. y Kemelmajer de Carlucci, A. (2012) "Fundamentos del Anteproyecto de Código Civil y Comercial de la Nación”. Recuperado: 25/11/2015.Disponible en: http://www.lavoz.com.ar/files/FUNDAMENTOS_DEL_ANTEPROYECTO_DE_CODIGO_ CIVIL_Y_COMERCIAL_DE_LA_NACION.pdf

Lorenzetti, R. (Dir. 2015) Código Civil y Comercial de la Nación Comentado. Tomo VIII. Santa Fe: Rubinzal - Culzoni.

Monjo, S. y Argañaraz, M. (2015) "Funciones de la responsabilidad civil. Función preventiva”. En: MÁRQUEZ, J. F. (Dir.) (2015) Responsabilidad Civil en el Código Civil y Comercial. Buenos Aires: Zavalía.

Pizarro, R. y Vallespinos, C. (1999) Instituciones de Derecho Privado. Obligaciones. Tomo 3. Buenos Aires: Hammurabi.

Prevot, J. M. (2011) "La función de la responsabilidad civil y los daños punitivos”. Revista de Derecho de Daños, 2011 (2). Buenos Aires: Rubinzal - Culzoni.

Rivera, J.C. (2004) Instituciones de Derecho Civil - Parte General. Buenos Aires: Abeledo Perrot.

Sozzo, G. (2013) “Arquitectura de la responsabilidad civil en el Proyecto de Código Civil y Comercial 2012 (post-Derecho de daños)”. En: MOSSET ITURRASPE, J. y LORENZETTI, R. Revista de Derecho de Daños. 2012 - 3. Proyecto de Código Civil y Comercial. Santa Fe: Rubinzal - Culzoni.

Trigo Represas, F y Lopez Mesa, M. (2004) Tratado de la responsabilidad civil. Tomo I. Buenos Aires: LA LEY.

Vázquez Ferreyra, R. (2011) Ley de defensa del consumidor. Buenos Aires: La Ley. 
Vergara, L. (2011) "La multa civil. Finalidad de prevención. Condiciones de aplicación en la legislación argentina”. Revista de Derecho de Daños, 2011 (2). Buenos Aires: Rubinzal - Culzoni.

ZAVALA DE GONZÁLEZ, M. (2015) La responsabilidad civil en el nuevo Código. Tomo I. Córdoba: Alveroni Ediciones.

\section{CURRICULUM VITAE}

\section{Sandra Natalia Umansky}

Abogada, egresada de la Facultad de Derecho, Ciencias Sociales y Políticas de la UNNE. Experta Universitaria en Responsabilidad Social Corporativa de la UNED, España. Becaria de Perfeccionamiento Tipo B de la Secretaría General de Ciencia y Técnica de la UNNE. Jefe de Trabajos Prácticos (interina) de la Cátedra Derecho Empresario de la Facultad de Ciencias Económicas de la UNNE. Alumna del Doctorado en Derecho de la Facultad de Derecho, Ciencias Sociales y Políticas de la UNNE.

sandraumansky@yahoo.com.ar 